\title{
Methylphenidate dose optimization for ADHD treatment: review of safety, efficacy, and clinical necessity
}

This article was published in the following Dove Press journal:

Neuropsychiatric Disease and Treatment

4 July 2017

Number of times this article has been viewed

\author{
Michael Huss' \\ Praveen Duhan ${ }^{2}$ \\ Preetam Gandhi ${ }^{3}$ \\ Chien-Wei Chen ${ }^{4}$ \\ Carsten Spannhuth ${ }^{3}$ \\ Vinod Kumar ${ }^{5}$ \\ 'Child and Adolescent Psychiatry, \\ University Medicine, Mainz, Germany; \\ ${ }^{2}$ Global Medical Affairs, Novartis \\ Healthcare Pvt. Ltd., Hyderabad, India; \\ ${ }^{3}$ Development Franchise, Established \\ Medicine Neuroscience, Novartis \\ Pharma AG, Basel, Switzerland; \\ ${ }^{4}$ Biostatistics Cardio-Metabolic \& \\ Established Medicine, Novartis \\ Pharmaceuticals Corporation, East \\ Hanover, NJ, USA; ${ }^{5}$ Established \\ Medicines, Novartis Pharmaceuticals \\ Corporation, East Hanover, NJ, USA
}

Correspondence: Vinod Kumar Novartis Pharmaceuticals Corporation, One Health Plaza, East Hanover, NJ 07936-1080, USA

Tel +l 8627787230

Fax +| $97378 \mid 8265$

Email vinod.kumar@novartis.com

\begin{abstract}
Attention-deficit/hyperactivity disorder (ADHD) is a chronic psychiatric disorder characterized by hyperactivity and/or inattention and is often associated with a substantial impact on psychosocial functioning. Methylphenidate (MPH), a central nervous system stimulant, is commonly used for pharmacological treatment of adults and children with ADHD. Current practice guidelines recommend optimizing MPH dosage to individual patient needs; however, the clinical benefits of individual dose optimization compared with fixed-dose regimens remain unclear. Here we review the available literature on MPH dose optimization from clinical trials and real-world experience on ADHD management. In addition, we report safety and efficacy data from the largest MPH modified-release long-acting Phase III clinical trial conducted to examine benefits of dose optimization in adults with ADHD. Overall, MPH is an effective ADHD treatment with a good safety profile; data suggest that dose optimization may enhance the safety and efficacy of treatment. Further research is required to establish the extent to which short-term clinical benefits of MPH dose optimization translate into improved long-term outcomes for patients with ADHD.
\end{abstract}

Keywords: methylphenidate, dose optimization, attention-deficit/hyperactivity disorder, ADHD

\section{Introduction}

Attention-deficit/hyperactivity disorder (ADHD) is one of the most common chronic childhood-onset psychiatric disorders, with an estimated global prevalence of $5.9 \%-7.1 \%$ among children/adolescents and $1.2 \%-7.3 \%$ among adults. ${ }^{1-3}$ ADHD was initially considered a childhood disorder that dissipated by adolescence or adulthood ${ }^{4}$; however, it is now defined as a chronic disorder that is reported to persist into adulthood in $\sim 30 \%-80 \%$ of those who retrospectively reported childhood ADHD. ${ }^{5-7}$ Children with ADHD are often characterized as hyperactive, and adults with ADHD are more likely to experience inner restlessness, an inability to relax, overtalkativeness, inattention, poor planning, and impulsivity. ${ }^{6,8,9}$ ADHD has a significant impact on psychosocial functioning (lower level of education, higher level of unemployment, and higher rates of unsuccessful marriages, criminality, and road traffic accidents). ${ }^{10,11}$

Treatment strategies for ADHD include both pharmacological and psychological therapies aimed to improve the core symptoms of ADHD (hyperactivity, impulsivity, and inattention) and associated functional impairments. Psychostimulants, including methylphenidate (MPH) and amphetamine-based treatments, are the most commonly prescribed pharmacological treatments for adults and children with ADHD. ${ }^{12-14}$ Despite 
being one of the mainstay treatments for ADHD, MPH use remains off-label for adults in some countries. ${ }^{15,16}$

Based on the efficacy data from randomized controlled trials and meta-analyses, MPH is now a widely accepted treatment for ADHD. ${ }^{17,18}$ Moreover, MPH is also reported to reduce the social, health, economical, and functional impairments experienced by ADHD patients. ${ }^{6,19-22}$ However, response to MPH treatment varies significantly between patients. ${ }^{17,23,24}$ Thus, certain patients may not achieve adequate symptom control, while others are unable to tolerate the same dose of MPH because of adverse events (AEs). ${ }^{25-28}$ Recent guidelines recommend tailoring MPH dosage to individual patient's needs (referred to as dose optimization, dose individualization, or flexible dose; Table 1). ${ }^{29-31}$ However, no head-to-head studies have directly compared benefits of flexible- versus fixed-dose treatment regimens.

The present review examines the recommendations for dose optimization in recent ADHD treatment guidelines, and the use of dose optimization in randomized clinical trials, as well as naturalistic studies. In addition, previously unpublished analysis from the largest MPH modified-release long-acting (MPH-LA) trial is presented to highlight the potential efficacy and safety benefits of dose optimization versus randomized fixed-dose regimens.

\section{Dose optimization in clinical practice}

Dose optimization is used routinely in general medicine and psychiatry to ensure optimal clinical effect, while minimizing the risk of AEs. Dose optimization is common for almost all psychotropic medications and may be crucial, particularly when considering clinical dose-response relationships with high interindividual variation, such as the use of stimulants for treatment of ADHD. ${ }^{32,33}$ Various factors can influence the need for dose optimization including genetic variability, patient weight, age, sex, drug-induced tolerance, and interactions with other medications or medical conditions. The length of time required and the method used to optimize dosage can vary extensively between pharmacological treatments.

MPH has a wide interindividual variability in dose response. In a meta-analysis of 18 randomized controlled trials, Castells et al found a positive dose-response relationship between MPH and ADHD symptoms in adults; however, in large clinical trials investigating a range of various MPH formulations, no dose-response relationship was found in adults with ADHD. ${ }^{17,34-36}$

Moreover, the dose-response relationship of MPH has also been debated in pediatric studies. Reportedly, a dose-response relationship was observed with osmotic-controlled release oral delivery system methylphenidate (OROS-MPH) in children with combined-type ADHD, whereas such a relationship was not noted in children with ADHD of a predominantly inattentive subtype. ${ }^{37}$ Furthermore, the association between dose optimization and weight remains inconclusive; some studies have reported no relationship between the final optimal dose and body weight, while others have indicated weight as a reliable clinical parameter for dose optimization. ${ }^{38-40}$ Douglas et al reported a linear dose-response relationship between dose $(0.15,0.30$, and $0.60 \mathrm{mg} / \mathrm{kg})$ and improvements in performance. ${ }^{41}$ This substantial intersubject variability has prompted the use of dose optimization in ADHD management.

\section{MPH dose optimization: current recommendations}

A number of European guidelines, including Swedish ADHD and National Institute for Health and Care Excellence (NICE) guidelines, recommend MPH as the first-line pharmacological treatment for adults and children with severe impairment (or moderate impairment but nonresponsive to nonpharmacological interventions). ${ }^{29,42} \mathrm{MPH}$ is available as an immediaterelease (MPH-IR) tablet and in a variety of modified-release formulations including long-acting formulations, topical patches, and extended-release formulations. ${ }^{43-48}$ In accordance with most ADHD treatment guidelines (eg, NICE), product guidelines recommend that MPH-naïve patients must be initially treated at low doses, and the doses should be increased on an individual basis until optimal response is achieved without an AE. ${ }^{43-48}$ Several ADHD treatment guidelines recommend that long- or short-acting stimulant medications should be prescribed based on individual patient needs. ${ }^{16,29,49}$ However, other guidelines recommend the use of long-acting stimulants as first-line treatment. ${ }^{30}$

European, Australasian, and North American ADHD guidelines support the use of pharmacotherapy for children with severe ADHD, children with moderate ADHD who are nonresponsive to behavioral therapy, and adults with moderate or severe ADHD. Collectively, these guidelines also highlight the need for dose titration and optimization of pharmacological therapy (Table 1). ${ }^{6,29-31}$ Moreover, the Canadian Attention Deficit Hyperactivity Disorder Resource Alliance guidelines recommend regular follow-ups to ensure treatment efficacy and tolerability. ${ }^{30}$ It is important to note that treatment guidelines vary regarding how dose optimization should be managed. Certain guidelines define optimal treatment as the dose above which there is no further improvement, whereas other guidelines recommend using 
Table I Methylphenidate Treatment Guidelines: International and National ADHD Treatment recommendations ${ }^{\mathrm{a}}$

\begin{tabular}{|c|c|}
\hline Guidelines (country; year) & Treatment recommendations \\
\hline \multirow[t]{2}{*}{ AAP Guidelines (US; 20II) $)^{31}$} & Children and adolescents \\
\hline & Clinicians should titrate doses of medication to achieve maximum benefit with minimum adverse effects \\
\hline BAP Guidelines & Children, adolescents, and adults: \\
\hline $\begin{array}{l}\text { (Great Britain; } 2007 \text {, } \\
\text { updated in } 2014)^{71,72}\end{array}$ & $\begin{array}{l}\text { For immediate- or modified-release preparations of methylphenidate, titration to the optimal dose should take } \\
\text { place over a } 4 \text { - to } 6 \text {-week period (maximum dose of } 60 \mathrm{mg} / \text { day for adolescents and children; and } 100 \mathrm{mg} / \text { day for } \\
\text { adults) }\end{array}$ \\
\hline CADDRA Guidelines & Children, adolescents, and adultsc: \\
\hline$(\text { Canadian; 20I I })^{30}$ & $\begin{array}{l}\text { Clinicians should start with low doses of medication and slowly increase the dose until the optimald treatment } \\
\text { dose is reached }\end{array}$ \\
\hline ESCAP Guidelines & Children, adolescents, and adultse: \\
\hline (European Guidelines; 2004) $)^{73}$ & $\begin{array}{l}\text { Clinicians should initiate treatment at a low dose }(0.2 \mathrm{mg} / \mathrm{kg} / \mathrm{dose} \text { for children and adolescents }) \text { and treatment } \\
\text { should be increased until a good result is achieved, or adverse effects appear, or the maximum dose is reached } \\
(0.7 \mathrm{mg} / \mathrm{kg} / \text { dose for children and adolescents }) \text { - whichever comes first }\end{array}$ \\
\hline New Zealand Ministry of & Children, adolescents, and adults: \\
\hline Health Guidelines $(200 \mathrm{I})^{49}$ & $\begin{array}{l}\text { Dosage should be individually titrated, starting at the lower end of the dose range (about } 0.1-0.2 \mathrm{mg} / \mathrm{kg} \text { ). The } \\
\text { dosage should be raised as needed (up to } 60 \mathrm{mg} / \text { day for children and adolescents), and at a pace that will vary } \\
\text { with the intensity depending on treatment effect and side effects } \\
\text { Dosage should be maintained at the smallest dose for optimal }{ }^{8} \text { therapeutic response }\end{array}$ \\
\hline Malaysian Guidelines $(2008)^{74}$ & $\begin{array}{l}\text { Children, adolescents, and adults } \mathrm{h}^{\mathrm{h}} \text { : } \\
\text { Dose titration, starting at the lower end of the dose range }(2.5 \mathrm{mg} / \text { day, aged } 3-5 \text { years; } 5 \mathrm{mg} / \text { day, aged } 8 \text { years; } \\
10 \mathrm{mg} / \text { day, aged }>8 \text { years), should be used to achieve the highest efficacy with minimal side effects (maximum } \\
\text { dosage up to } 60 \mathrm{mg} / \text { day; up to } 30 \mathrm{mg} / \text { day, aged } 3-5 \text { years) }\end{array}$ \\
\hline NICE Guidelines (England and & Children and adolescents: \\
\hline \multirow[t]{5}{*}{ Wales; updated 2016$)^{29}$} & $\begin{array}{l}\text { Initial treatment with methylphenidate should begin with low doses of immediate-release }(5 \mathrm{mg} \text { twice or three } \\
\text { times, daily) or modified-release preparations }\end{array}$ \\
\hline & $\begin{array}{l}\text { The dose should be titrated against symptoms and side effects over } 4-6 \text { weeks until dose optimization is } \\
\text { achieved (maximum dosage up to } 60 \mathrm{mg} / \text { day) }\end{array}$ \\
\hline & Adults: \\
\hline & $\begin{array}{l}\text { Initial treatment should begin with low doses ( } 5 \mathrm{mg} \text { three times daily for immediate-release preparations; the } \\
\text { equivalent dose for modified-release preparations) }\end{array}$ \\
\hline & $\begin{array}{l}\text { The dose should be titrated against symptoms and side effects over 4-6 weeks and the dose should be increased } \\
\text { according to response (maximum dose of } 100 \mathrm{mg} / \text { day) }\end{array}$ \\
\hline NHMRC Guidelines & Children and adolescents: \\
\hline$(\text { Australian; 2012) })^{75}$ & Treatment and dosage must be tailored effectively to the individual needs of the child/adolescent \\
\hline SIGN Guidelines & Children and adolescents: \\
\hline$(\text { Scottish; 2009) })^{76}$ & Clinicians should follow a structured titration protocol so that the optimum dose of medication is established \\
\hline \multirow[t]{3}{*}{ Spanish Guidelines $(2010)^{77}$} & Children and adolescents: \\
\hline & $\begin{array}{l}\text { Clinicians should start with low doses ( } 2.5 \text { or } 5 \mathrm{mg} \text { depending on the child's weight; } 2-3 \text { times daily) of } \\
\text { immediate-release methylphenidate }\end{array}$ \\
\hline & $\begin{array}{l}\text { The dose should be increased progressively }(2.5-5 \mathrm{mg} \text { a week depending on the clinical response and presence } \\
\text { of side effects) to a maximum dose of } 60 \mathrm{mg} / \text { day }\end{array}$ \\
\hline \multirow[t]{4}{*}{ Swedish Guidelines $(2016)^{42}$} & Children and adolescents: \\
\hline & $\begin{array}{l}\text { Clinicians should initiate treatment at a low dose ( } 18 \mathrm{mg} \text { for long-acting; 5-10 mg for intermediate-acting) and } \\
\text { adjust the dose incrementally (approximately once per week) until a dose that provides good effect and is well } \\
\text { tolerated is reachedk }\end{array}$ \\
\hline & Adults: \\
\hline & $\begin{array}{l}\text { Clinicians are advised to begin treatment at a low dose and gradually increase (usually on a weekly basis) it to a } \\
\text { dose that provides the best balance between efficacy and adverse effects (maximum dosage up to } 80 \mathrm{mg} / \text { day) }\end{array}$ \\
\hline
\end{tabular}

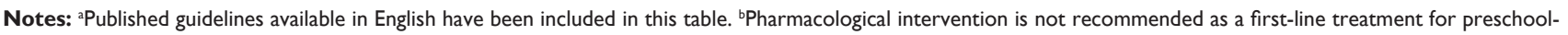
age children (aged $<6$ years). 'Treatment before the age of 6 years, if necessary, should only be done under the direction of a specialist. ${ }^{\mathrm{d} O p t i m a l}$ treatment means that the symptoms have decreased and that there is improvement in general functioning. Optimal dose is also that dose above which there is no further improvement. Sometimes side effects limit the dose titration. ${ }^{e}$ Careful and detailed titration of dosage and timing is likely to improve response. ${ }^{f}$ Treatment for adults, if necessary, should only be done under the direction of a specialist. ${ }^{8}$ Titration schedules for specific pharmacological treatments are presented in the CADDRA Guidelines. ${ }^{\mathrm{h}}$ Optimal treatment depends on the balance of best improvement of the most significant problem, relatively lesser effect on other problems and existence of any side effects. 'Dosage is usually not calculated based on body weight; however, the dosage range based on the body weight may be a guide during titration. iDosage should be consistent with starting doses in the BNF. kDose escalation should not be interrupted too early. It may be better to try a higher dose that can be reduced if adverse effects occur in order to achieve an optimal balance between efficacy and adverse effects.

Abbreviations: AAP, American Academy of Pediatrics; ADHD, attention-deficit/hyperactivity disorder; BAP, British Association for Psychopharmacology; BNF, British National Formulary; CADDRA, Canadian ADHD Resource Alliance; ESCAP, European Society for Child and Adolescent Psychiatry; AD, not applicable; NICE, National Institute for Health and Care Excellence; NIMH, National Institute of Mental Health; NHMRC, National Health and Medical Research Council; SIGN, Scottish Intercollegiate Guidelines Network. 
the lowest dose necessary to achieve optimal therapeutic response..$^{30,49}$ Therefore, methods of optimization tend to vary between clinical studies. In certain trials, doses have been increased until the patient responds or until the maximum dose is reached.$^{50}$ In other studies, doses have been increased until the occurrence of an AE, whereby the dose was then decreased to the previously tolerated dose. ${ }^{34}$ Another way to find an optimal dose is the use of a blinded $\mathrm{N}=1$ strategy, where different doses are given to the patient in a blinded manner to find the best balance between symptom control and possible AEs. Although blinded $\mathrm{N}=1$ trials are a promising way of dose optimization at the individual patient level, they are not widely used as they are considered time-consuming and no standards are established on possible ranges, duration of drug or placebo exposure, and titration schedules on the $\mathrm{N}=1$ level.

Despite a high level of consistency between national and international treatment guidelines (Table 1) and MPH product labels, in the real-world clinical treatment of ADHD, health care providers may not adhere to these recommendations. ${ }^{43-48}$ Goodman et al $^{51}$ reported that a high proportion of family physicians are not confident with diagnosing and treating adult ADHD. A survey of 1,216 primary care physicians (PCPs) revealed that $31 \%$ of PCPs rated themselves as "not confident" when diagnosing adult ADHD, and 36\% were "not confident" regarding treatment. In the same survey, psychiatrists were more confident with diagnosis and treatment of ADHD. Furthermore, a recently published US study of over 1,500 patient charts from 188 pediatricians across 50 different practices, from August 2002 through December 2012, demonstrated that community-based ADHD care was not consistent with the guidelines. ${ }^{52}$ Overall, only $47.4 \%$ of children prescribed medication had contact (phone contact or visit) with their pediatrician within the first month of their prescription, and parent- and teacher-rating scales were rarely collected to monitor treatment response or side effects. These data indicate the need for improved awareness of how best to manage pharmacological dose titration to achieve optimal dosage.

\section{Dose optimization in clinical trials and naturalistic studies $\mathrm{MPH}$ dose optimization in clinical trials}

Although MPH dose optimization is recommended in the ADHD treatment guidelines, and clinical trials report flexible-dose therapy, fixed-dose therapy, or a combination of both, analyses of the clinical benefits of dose optimization versus fixed-dose regimens for patients are limited.
A recent meta-regression analysis of 18 randomized, placebo-controlled studies compared the outcomes of MPH clinical trials that included flexible-dose regimens (12 studies; 1,327 adults with ADHD) to those that included fixed-dose regimens (6 studies; 718 adults with ADHD). ${ }^{17}$ However, none of the trials included in their analysis directly compared fixed- versus flexible-dose regimens.

Recent randomized, controlled ADHD trials that have incorporated a flexible-dose regimen have reported that a range of $\mathrm{MPH}$ doses are required to effectively treat patients. ${ }^{38,50,53-56}$ In a randomized, placebo-controlled trial (Figure 1), Huss et $\mathrm{al}^{53}$ reported that several doses of MPH-LA (40, 60, and $80 \mathrm{mg})$ were determined to be optimal for a similar number of ADHD patients $(n=152$, $n=177$, and $n=160$, respectively). Further analysis of the MPH-LA study data showed that this was irrespective of the initial dose administered during Period 1 (Figure 2; previously unpublished data). Similarly, other clinical trials have also reported that multiple doses of MPH are required for adequate treatment of adults and children with ADHD. Buitelaar et $\mathrm{al}^{54}$ reported that a range of OROS-MPH doses are required; overall, $7.9 \%$ of patients completed the study on $18 \mathrm{mg}$ of OROS-MPH, $29.3 \%$ on $36 \mathrm{mg}, 34.4 \%$ on $54 \mathrm{mg}, 19.8 \%$ on $72 \mathrm{mg}$, and $8.7 \%$ on $90 \mathrm{mg}$. In another study wherein children and adolescents treated with MPH extended-release, a number of doses were also required for optimal treatment ${ }^{38}$; overall, $27.7 \%$ of pediatric patients had received a final open-label dose of $30 \mathrm{mg}, 25.2 \%$ had $40 \mathrm{mg}$, $17.8 \%$ had $50 \mathrm{mg}, 16.8 \%$ had $20 \mathrm{mg}, 8.9 \%$ had $60 \mathrm{mg}, 2.0 \%$ had $15 \mathrm{mg}$, and $1.5 \%$ had $10 \mathrm{mg}$. The need for multiple doses of MPH to achieve effective symptom control further highlights the importance of an individualized or tailored treatment approach for ADHD. Recently, Chermá et al ${ }^{40}$ reported a large variation in the optimal treatment dose of 59 patients with ADHD; however, blood sample analysis revealed that the median daily dose per body weight was similar $(\sim 1.0 \mathrm{mg} / \mathrm{kg})$. As per the available literature, genetic differences may lead to significant variability in pharmacokinetic profiles across the day at an individual level, which may result in the large variation observed. ${ }^{58}$

\section{MPH dose optimization in naturalistic and open-label extension studies}

Recent noninterventional or naturalistic studies have examined the efficacy and/or safety of MPH in children, adolescents, or adults with ADHD. ${ }^{57}$ Fredriksen et al conducted a naturalistic study to assess the 1-year efficacy of ADHD treatment regimens in adults with ADHD. ${ }^{59}$ All patients 


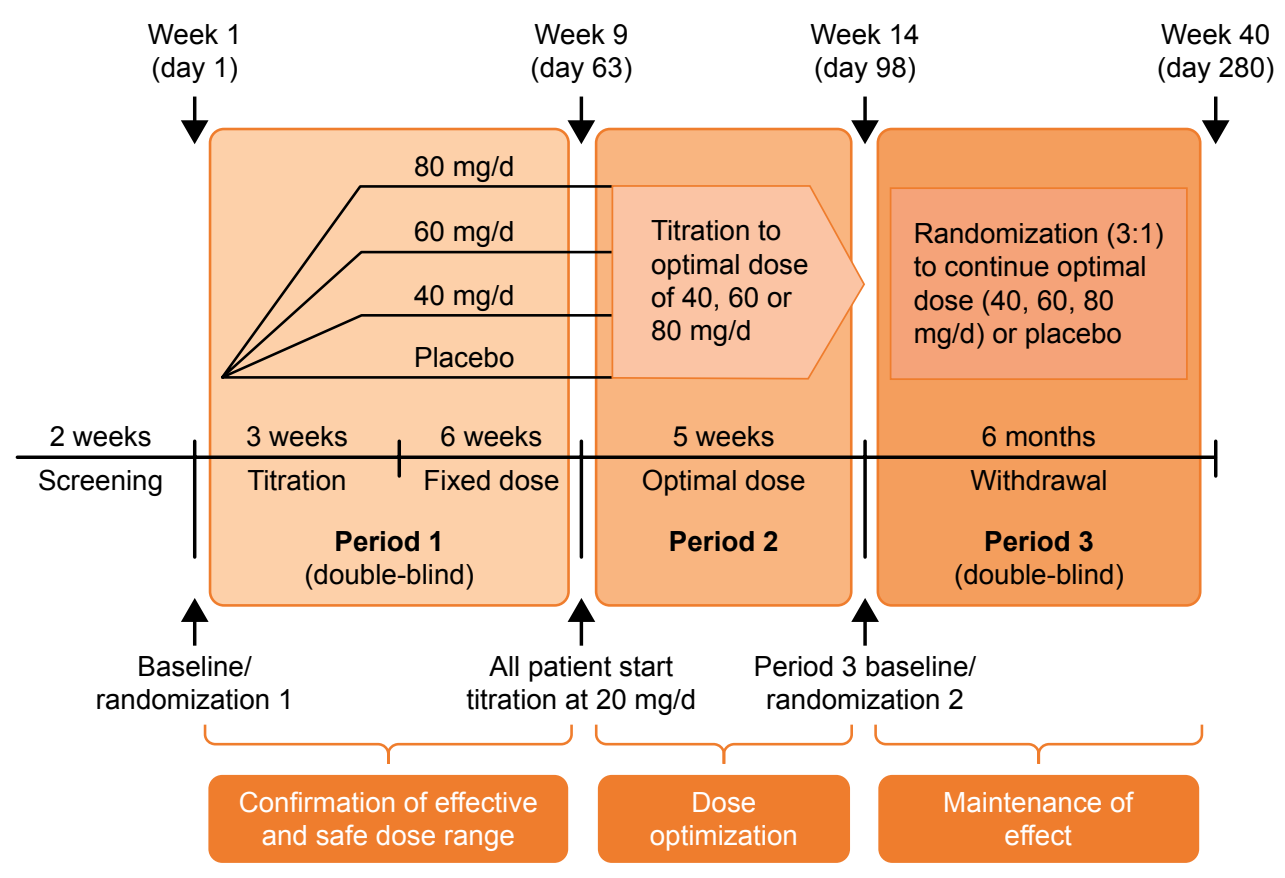

Figure I The MPH-LA trial design includes a combination of fixed-dose (Period I) and flexible-dose (Period 2 and Period 3 ) periods in a single study to assess the efficacy of MPH-LA in adult ADHD and to identify the individualized optimal dose for patients. Reproduced from Huss M, Ginsberg Y, Tvedten T, et al. Methylphenidate hydrochloride modified-release in adults with attention deficit hyperactivity disorder: a randomized double-blind placebo-controlled trial. Adv Ther. 20I4;3I(I):44-65. ${ }^{34}$

Abbreviations: ADHD, attention-deficit/hyperactivity disorder; MPH-LA, methylphenidate modified release long-acting formulation.

received MPH as the first-line pharmacological treatment in addition to psychosocial interventions. The study was conducted at a specialized outpatient clinic in Norway and involved a 6-week MPH titration phase (up to $60 \mathrm{mg} /$ day) followed by a dose-optimization phase (maximum dose $120 \mathrm{mg}$ /day). Under these real-world conditions, $\sim 70 \%$ of patients completed the 1-year study phase without discontinuing pharmacological treatment: 128 patients continued to receive MPH, 25 had switched to dextroamphetamine, and 10

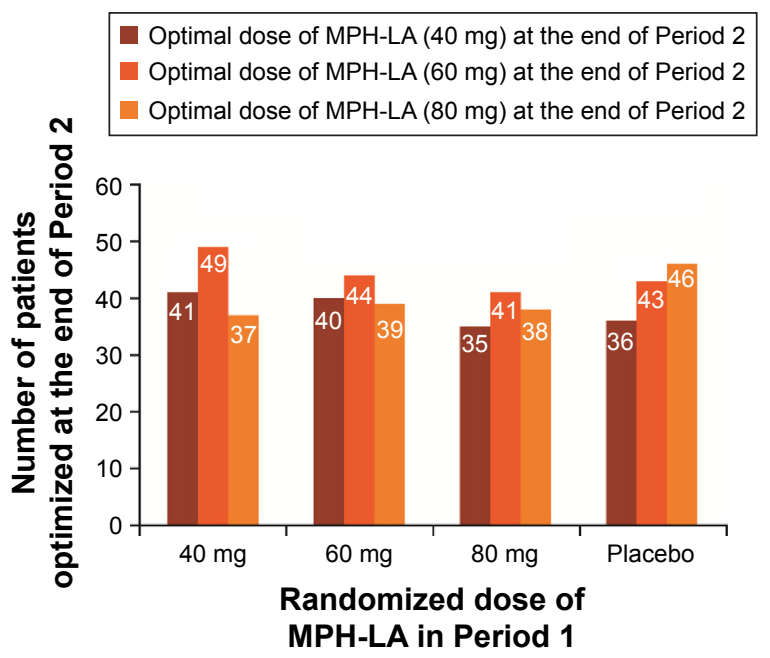

Figure 2 Individualized optimal dose achieved at the end of the open-label, flexibledose (Period 2) shown by randomized dose received in Period I.

Abbreviation: MPH-LA, methylphenidate modified-release long-acting formulation. had switched to atomoxetine. In line with randomized, controlled clinical trials, AEs and lack of efficacy were reported as the most common reasons for treatment discontinuation. ${ }^{59,60}$ Moreover, the study revealed that approximately half of the patients preferred immediate-release MPH over extendedrelease formulations, highlighting the need for clinicians to consider alternative MPH formulations on an individual patient basis.

Cortese et al have recently published long-term MPH-IR safety data from the Italian National ADHD Registry ${ }^{61}$; similar to the study conducted by Fredriksen et al, treatment was individualized based on clinical response and tolerability (maximum dose $0.6 \mathrm{mg} / \mathrm{kg} /$ dose) ${ }^{59}$ The safety profile was favorable as $25.9 \%$ of MPH-treated patients had experienced at least one mild $\mathrm{AE}$ and $4.5 \%$ had experienced at least one severe AE. ${ }^{61}$

Open-label extension studies of randomized controlled trials have provided evidence regarding the long-term benefits and safety of dose-optimized MPH treatment. ${ }^{53,63-65}$ Buitelaar et al evaluated the long-term efficacy and tolerance of OROS-MPH, wherein no evidence of withdrawal or rebound was reported after treatment discontinuation. ${ }^{64}$ As previously reported in randomized controlled trials, the most common reason reported for treatment discontinuation was AE. ${ }^{60}$ Ginsberg et al reported a lower rate $(2.3 \%)$ of AE-induced discontinuation during the extension phase of 
the MPH-LA study compared with other open-label extension studies such as OROS-MPH (18.5\%). ${ }^{55,63}$ They suggested that this was because of the use of flexible-dose regimens, which was allowed during the extension phase of the study.

\section{MPH-LA clinical trial: design and analysis}

Huss et al designed the only clinical trial (NCT01259492) including both fixed- and flexible-dose phases that directly investigated the benefits of flexible-dose regimens. ${ }^{34,53}$ This MPH-LA trial encompassed both fixed-and flexible dosing in a single patient cohort (Figure 1). ${ }^{34,53}$ This MPH-LA trial was a 40-week, randomized, double-blind, placebo-controlled, multicenter, efficacy and safety study of MPH-LA in the treatment of adult patients with childhood-onset ADHD. The primary objectives of the trial were to 1) confirm the clinically effective dose range; 2) confirm the maintenance effect of MPH-LA; and 3) evaluate safety profile of MPH-LA vs placebo. The threephase study design also allowed for post hoc analysis of the benefits of dose optimization. ${ }^{53}$ Symptomatic and functional responses to MPH-LA were evaluated using validated instruments, including the Diagnostic and Statistical Manual of Mental Disorders, 4th edition Attention-Deficit/Hyperactivity Disorder Rating Scale (DSM-IV ADHD RS), and Sheehan Disability Scale (SDS) ${ }^{66,67}$ Published results demonstrate that dose optimization of MPH-LA is possible, sudden switching between doses is safe, dose optimization with MPH-LA (40, 60 , or $80 \mathrm{mg} /$ day) improves symptomatic and functional treatment outcomes, and numerous doses of MPH-LA are required for optimal treatment of adult ADHD. ${ }^{34,53}$

Few other studies have also included an initial fixed-dose period followed by MPH dose optimization; however, these studies have not assessed the benefits of dose optimization. Wigal et al reported that pediatric patients continued to improve during an 11-week dose-optimization phase (openlabel period). ${ }^{38}$ In addition, Buitelaar et al reported that following a 7-week open-label extension of the fixed-dose LAMDA study with a flexible dose of OROS-MPH dose (18-90 mg/day), ADHD patients experienced improvements in symptoms, ability to function, and quality of life. ${ }^{54,68}$ This was irrespective of whether they received placebo or OROS$\mathrm{MPH}$ during the fixed-dose phase.

\section{Optimized dosing: clinical efficacy and functional improvement in the MPH-LA trial}

Here we present previously unpublished post hoc analysis from the MPH-LA clinical trial (Figures 2 and 3; Table 2). ${ }^{34}$
This post hoc analysis was conducted using the analysis of covariance model, with treatment and center as factors and baseline score as a covariate, to assess the benefits of dose optimization. DSM-IV ADHD RS and SDS scores were retrospectively analyzed for Period 1 based on patients' optimal dose, as determined during Period 2. Patients were then divided into four groups: placebo, patients who received their optimal dose, patients who received more than their optimal dose, and patients who received less than their optimal dose during Period 1 (Figure 3A and B).

Patients who received their optimal dose of MPH-LA during Period 1 exhibited the highest average improvements in DSM-IV ADHD RS and SDS total scores from baseline (Figure 3A and B, respectively). The highest improvement in DSM-IV ADHD RS (Figure 3A) was seen in patients who received their optimal dose (18.99: $P<0.0001$ vs placebo), followed by patients who received greater than their optimal dose (17.78: $P<0.0001$ vs placebo), and then those who received less than their optimal dose (14.10: $P=0.0093$ vs placebo). The improvement from baseline in SDS total score (Figure 3B) was greater in patients who received their optimal dose (7.41: $P<0.0001$ vs placebo) compared with those who received more than their optimal dose (6.86: $P=0.0003$ vs placebo) and those who received less than their optimal dose (5.28: $P=0.0506$ vs placebo) during Period 1 .

\section{Optimized dose: safety profile of MPH in the MPH-LA trial}

MPH treatment is associated with several challenges, including high rates of mild-to-moderate AEs, poor compliance, high treatment discontinuation rates, and high rates of intersubject variability in response. A systematic review of literature revealed that AEs are one of the most common reasons for treatment discontinuation. ${ }^{60}$ The most common AEs reported with MPH included headaches, decreased appetite, dry mouth, nasopharyngitis, nausea, irritability, and insomnia. ${ }^{34,54} \mathrm{~A}$ recent meta-analysis revealed that $\mathrm{MPH}$ treatment was associated with an increased risk of nonserious AEs compared to placebo, but no increase in the risk of serious AEs. ${ }^{69}$ As with treatment efficacy, the relationship between dose and AEs remains unclear. In numerous MPH trials, a similar incidence of AEs, with the exception of decreased appetite and insomnia, was observed at all treatment doses. ${ }^{34,37}$ Moreover, the safety profile of MPH seems to be similar in pediatric and adult populations. ${ }^{70}$

For the purpose of this review, AEs in Period 1 of the Huss et al MPH-LA study were reanalyzed based on patients' known optimal dose from Period 2. ${ }^{34}$ Descriptive statistics 

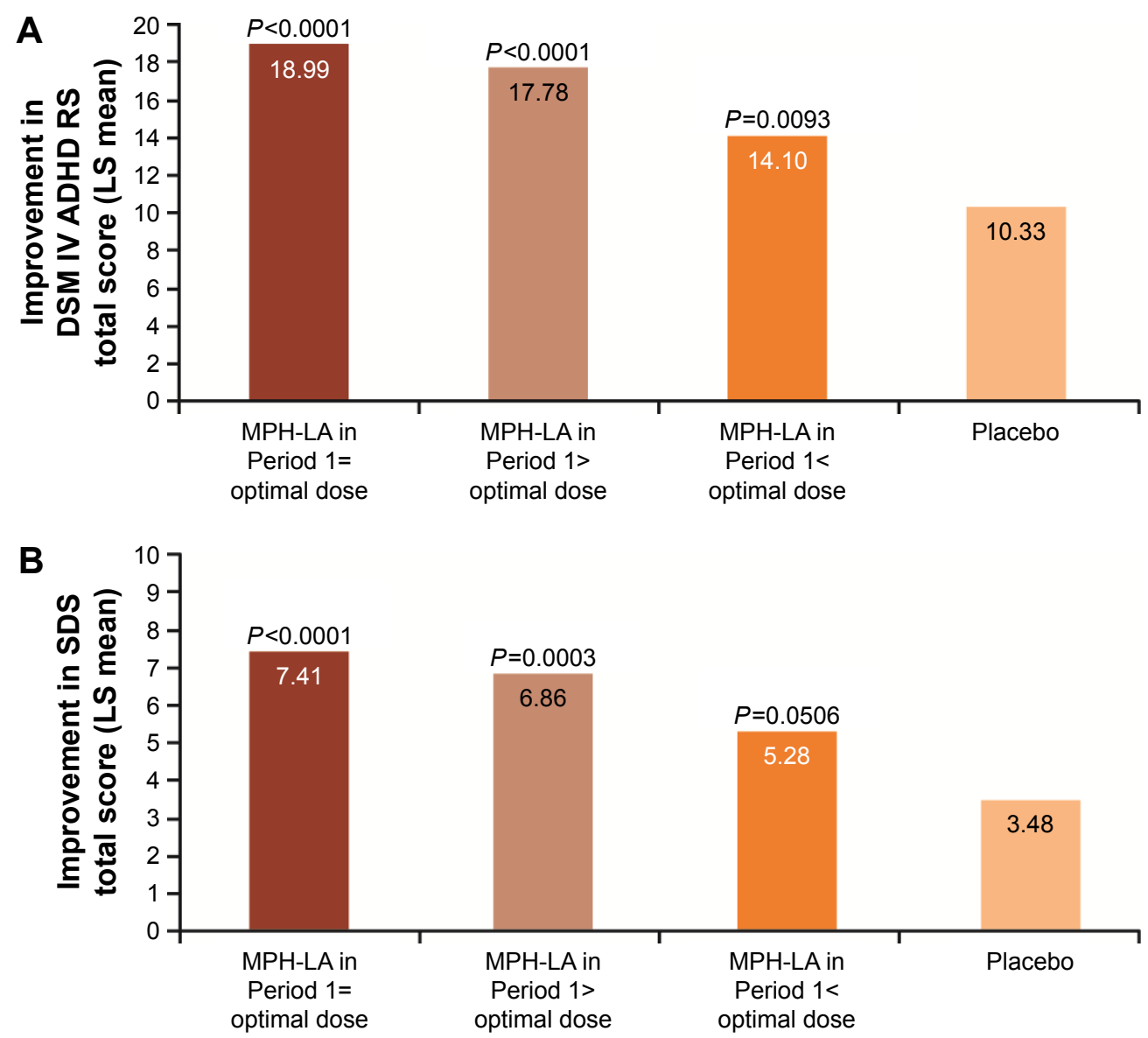

Figure 3 LS mean change in (A) DSM-IV ADHD RS ( $n=|19, n=1| 6, n=\mid 19$, and $n=\mid 18$, respectively) and $(\mathbf{B})$ SDS total $(n=|| 3, n=|| 5, n=|| 7$, and $n=|| 3$, respectively) score from baseline I to end of Period I by optimal dose achieved in Period 2. Data were analyzed using an analysis of covariance model with treatment and center as factors, and baseline score as a covariate. $P$-values correspond to each group versus placebo.

Abbreviations: DSM-IV ADHD RS, Diagnostic and Statistical Manual of Mental Disorders, 4th edition Attention-Deficit/Hyperactivity Disorder Rating Scale; LS mean, least square mean; MPH-LA, methylphenidate modified-release long-acting formulation; SDS, Sheehan Disability Scale.

were used for the AE data, and Table 2 summarizes the proportion of AEs that occurred in $\geq 5 \%$ of patients. Patients who received more than their optimal dose experienced the highest rate of AEs ( $82.8 \%$ of patients) compared with those who received their optimal dose $(68.3 \%)$ or less than their optimal dose (68.0\%). Moreover, the rate of cardiac disorders (palpitations and tachycardia) seemed to be associated with the individually optimized dose: $19.8 \%$ of patients who received greater than their optimal dose experienced cardiac AEs compared with $10.6 \%$ of patients who received their optimal dose and $4.8 \%$ of patients who received less than their optimal dose (Table 2). In addition, the proportion of patients who experienced decreased appetite was higher for those who received more than their optimal dose $(35.3 \%)$ than for patients who received their optimal dose $(25.2 \%)$ or less than their optimal dose $(19.2 \%)$. There was no association between AEs and optimal dose for gastrointestinal disorders, general disorders (fatigue and irritability), infections and infestations, musculoskeletal and connective tissue disorders, skin disorders, or central nervous system disorders (Table 2).

\section{Discussion and limitations}

There are limited data available regarding stimulant dose optimization versus fixed-dose regimens for ADHD. The MPH-LA study provides valuable insights into the clinical efficacy and safety benefits of optimized dosing; however, it was not specifically designed to assess this objective, and further research is needed to confirm the efficacy and safety benefits of dose optimization with MPH. ${ }^{34}$ Although dose optimization is reported in the majority of clinical trials and naturalistic studies, there is currently no data available regarding the use of dose optimization in general practice. Additionally, although the once-daily dosing regimen used in the MPH-LA adult study is optimal for scientifically investigating dosage, it does not mimic naturalistic realworld treatment regimens. As a result, there is a need to generate real-world data on the use of flexible dose in routine 
Table 2 Frequency of adverse events in Period I based on optimal dose achieved in Period 2

\begin{tabular}{|c|c|c|c|c|}
\hline Preferred term & $\begin{array}{l}\text { MPH-LA in Period } \\
\text { I=optimal dose } \\
(\mathbf{N}=\mathbf{I 2 3})\end{array}$ & $\begin{array}{l}\text { MPH-LA in Period I> } \\
\text { optimal dose }(\mathrm{N}=1 \mid 6)\end{array}$ & $\begin{array}{l}\text { MPH-LA in Period I }< \\
\text { optimal dose }(N=\mid 25)\end{array}$ & $\begin{array}{l}\text { Placebo } \\
(\mathrm{N}=\mid 25)\end{array}$ \\
\hline Total AEs & $84(68.3)$ & $96(82.8)$ & $85(68.0)$ & $70(56.0)$ \\
\hline Cardiac disorders & $13(10.6)$ & $23(19.8)$ & $6(4.8)$ & $\mathrm{I}(0.8)$ \\
\hline Palpitations & $8(6.5)$ & $14(12.1)$ & $3(2.4)$ & $\mathrm{I}(0.8)$ \\
\hline Tachycardia & $5(4.1)$ & $10(8.6)$ & $3(2.4)$ & $0(0.0)$ \\
\hline Gastrointestinal disorders & $44(35.8)$ & $45(38.8)$ & $45(36.0)$ & $18(14.4)$ \\
\hline Abdominal (upper) pain & $4(3.3)$ & $6(5.2)$ & $5(4.0)$ & $6(4.8)$ \\
\hline Diarrhea & $3(2.4)$ & $6(5.2)$ & $\mathrm{I}(0.8)$ & $7(5.6)$ \\
\hline Dry mouth & $29(23.6)$ & $26(22.4)$ & $24(19.2)$ & $\mathrm{I}(0.8)$ \\
\hline Nausea & $13(10.6)$ & $15(12.9)$ & $9(7.2)$ & $7(5.6)$ \\
\hline General disorders and administration conditions & $20(16.3)$ & $23(19.8)$ & $20(16.0)$ & $20(16.0)$ \\
\hline Fatigue & $7(5.7)$ & $10(8.6)$ & $8(6.4)$ & $8(6.4)$ \\
\hline Irritability & $6(4.9)$ & $8(6.9)$ & $6(4.8)$ & $7(5.6)$ \\
\hline Infections and infestations & $19(15.4)$ & $28(24.1)$ & $25(20.0)$ & $25(20.0)$ \\
\hline Nasopharyngitis & II (8.9) & $14(12.1)$ & II (8.8) & II (8.8) \\
\hline Investigations & II (8.9) & II (9.5) & $8(6.4)$ & $3(2.4)$ \\
\hline Metabolism and nutrition disorders & $3 \mid(25.2)$ & $4 \mathrm{I}(35.3)$ & $24(19.2)$ & $9(7.2)$ \\
\hline Decreased appetite & $31(25.2)$ & $4 \mathrm{I}(35.3)$ & $24(19.2)$ & $5(4.0)$ \\
\hline Musculoskeletal and connective tissue disorders & $8(6.5)$ & II (9.5) & $7(5.6)$ & $7(5.6)$ \\
\hline Nervous system disorders & $43(35.0)$ & $34(29.3)$ & $34(27.2)$ & $32(25.6)$ \\
\hline Dizziness & $6(4.9)$ & $9(7.8)$ & $7(5.6)$ & $5(4.0)$ \\
\hline Headache & $25(20.3)$ & $25(21.6)$ & $25(20.0)$ & $20(16.0)$ \\
\hline Psychiatric disorders & $4 \mathrm{I}(33.3)$ & $42(36.2)$ & $23(18.4)$ & $18(14.4)$ \\
\hline Anxiety & $6(4.9)$ & $7(6.0)$ & $\mathrm{I}(0.8)$ & $0(0.0)$ \\
\hline Initial insomnia & $6(4.9)$ & $9(7.8)$ & $6(4.8)$ & $2(1.6)$ \\
\hline Insomnia & II (8.9) & $10(8.6)$ & $3(2.4)$ & $6(4.8)$ \\
\hline Restlessness & $6(4.9)$ & $6(5.2)$ & $\mathrm{I}(0.8)$ & $5(4.0)$ \\
\hline Sleep disorder & $7(5.7)$ & I (0.9) & $\mathrm{I}(0.8)$ & $2(1.6)$ \\
\hline Skin and subcutaneous tissue disorders & $14(11.4)$ & $15(12.9)$ & $9(7.2)$ & $8(6.4)$ \\
\hline Hyperhidrosis & II (8.9) & $14(12.1)$ & $7(5.6)$ & $4(3.2)$ \\
\hline
\end{tabular}

Notes: Data are presented as $n(\%)$. A patient with multiple occurrences of an AE under one treatment is counted only once in the AE category.

Abbreviations: $\mathrm{AE}$, adverse event; MPH-LA, methylphenidate modified-release long-acting formulation.

clinical practice. Murray and colleagues identified 13 electronic databases of ADHD health care records in Europe. ${ }^{62}$ In the future, these databases may provide additional insight into the long-term outcomes of ADHD patients.

This review has a number of potential limitations including that it was not a systematic literature review, and hence, the quality of the studies included in the review was not analyzed systematically. Although an extensive database was searched to identify relevant articles for inclusion, study inclusion may have been subject to the author and publication bias. Moreover, the methods of treatment optimization varied in different studies, which may impact the results; however, this was not considered while summarizing results in this review.

\section{Conclusion}

Dose optimization may improve patient satisfaction with stimulant therapy and could also enhance treatment effectiveness, patient compliance, and tolerability. The authors recommend that dose individualization should continue to be used (or implemented if not yet used) to improve patient functioning and reduce the social and economic burden of disease, in the pharmacological treatment of ADHD.

\section{Acknowledgments}

Medical writing support was provided by Áine Abautret-Daly (Novartis Ireland Ltd., Dublin, Ireland) and Anupama Tamta (Novartis Heathcare Pvt. Ltd., India). This service was supported by Novartis Pharma AG, Basel, Switzerland.

\section{Disclosure}

$\mathrm{MH}$ has received unrestricted grants to conduct Investigator Initiated Trials (IIT) with products of Engelhard Arzeimittel and Medice. He has received speaker honoraria and travel support and served as an advisor for Lilly, Shire, Medice, Novartis, Engelhard Arzneimittel, Acelion, and Lundbeck. 
He also holds an international patent on Doppler radar to assess ADHD. PD is an employee of Novartis Healthcare Pvt Ltd and has been working as Medical Affairs Director for the Established Medicines Franchise of Novartis Healthcare Pvt Ltd. PG is an employee of Novartis Pharma AG and has been working as Medical Director for the Established Medicines Franchise of Novartis Pharma AG. CWC is an employee of Novartis Pharmaceuticals Corporation. CS is a full-time employee of Novartis Pharma AG. VK is an employee of Novartis Pharmaceuticals Corporation and owns stocks in the company.

\section{References}

1. Moffitt TE, Houts R, Asherson P, et al. Is Adult ADHD a childhoodonset neurodevelopmental disorder? Evidence from a four-decade longitudinal cohort study. Am J Psychiatry. 2015;172:967-977.

2. Faraone SV, Antshel KM. Diagnosing and treating attention-deficit/ hyperactivity disorder in adults. World Psychiatry. 2008;7(3):131-136.

3. Polanczyk GV, Willcutt EG, Salum GA, Kieling C, Rohde LA. ADHD prevalence estimates across three decades: an updated systematic review and meta-regression analysis. Int J Epidemiol. 2014;43(2):434-442.

4. Hill JC, Schoener EP. Age-dependent decline of attention deficit hyperactivity disorder. Am J Psychiatry. 1996;153(9):1143-1146.

5. Turgay A, Goodman DW, Asherson P, et al. Lifespan persistence of ADHD: the life transition model and its application. J Clin Psychiatry. 2012;73(2):192-201.

6. Kooij SJ, Bejerot S, Blackwell A, et al. European consensus statement on diagnosis and treatment of adult ADHD: the European Network Adult ADHD. BMC Psychiatry. 2010;10:67.

7. Lara C, Fayyad J, de Graaf R, et al. Childhood predictors of adult attention-deficit/hyperactivity disorder: results from the World Health Organization World Mental Health Survey Initiative. Biol Psychiatry. 2009; 65(1):46-54.

8. European Medicines Agency E. Guideline on the clinical investigation of medicinal products for the treatment of attention deficit hyperactivity disorder (ADHD). eds; 2008. Available from: http://www.ema. europa.eu/docs/en_GB/document_library/Scientific_guideline/2010/08/ WC500095686.pdf. Accessed February, 2016.

9. American Psychiatric Association. Diagnostic and Statistical Manual of Mental Disorders. 5th ed, DSM-5. American Psychiatric Publishing; 2012. Available from: http://www.dsm5.org. Accessed February, 2017.

10. Goodman DW. The consequences of attention-deficit/hyperactivity disorder in adults. $J$ Psychiatr Pract. 2007;13(5):318-327.

11. Biederman J, Faraone SV, Spencer TJ, Mick E, Monuteaux MC, Aleardi M. Functional impairments in adults with self-reports of diagnosed ADHD: a controlled study of 1001 adults in the community. J Clin Psychiatry. 2006;67(4):524-540.

12. Morton WA, Stockton GG. Methylphenidate abuse and psychiatric side effects. Prim Care Companion J Clin Psychiatry. 2000;2(5): 159-164.

13. Safer DJ. Recent trends in stimulant usage. J Atten Disord. 2016; 20(6):471-477.

14. Renoux C, Shin JY, Dell'Aniello S, Fergusson E, Suissa S. Prescribing trends of attention-deficit hyperactivity disorder (ADHD) medications in UK primary care, 1995-2015. Br J Clin Pharmacol. 2016;82(3):858-868.

15. Trenque T, Herlem E, Abou Taam M, Drame M. Methylphenidate off-label use and safety. Springerplus. 2014;3:286.

16. Hodgkins P, Shaw M, Coghill D, Hechtman L. Amfetamine and methylphenidate medications for attention-deficit/hyperactivity disorder: complementary treatment options. Eur Child Adolesc Psychiatry. 2012;21(9):477-492.
17. Castells X, Ramos-Quiroga JA, Rigau D, et al. Efficacy of methylphenidate for adults with attention-deficit hyperactivity disorder: a meta-regression analysis. CNS Drugs. 2011;25(2):157-169.

18. Chan E, Fogler JM, Hammerness PG. Treatment of attention-deficit/ hyperactivity disorder in adolescents: a systematic review. JAMA. 2016; 315(18):1997-2008.

19. Lichtenstein $P$, Halldner L, Zetterqvist J, et al. Medication for attention deficit-hyperactivity disorder and criminality. $N$ Engl J Med. 2012;367: 2006-2014.

20. Konstenius M, Jayaram-Lindstrom N, Guterstam J, Beck O, Philips B, Franck J. Methylphenidate for attention deficit hyperactivity disorder and drug relapse in criminal offenders with substance dependence: a 24-week randomized placebo-controlled trial. Addiction. 2014;109(3): 440-449.

21. Man KK, Chan EW, Coghill D, et al. Methylphenidate and the risk of trauma. Pediatrics. 2015;135(1):40-48.

22. Shaw M, Hodgkins $\mathrm{P}$, Caci H, et al. A systematic review and analysis of long-term outcomes in attention deficit hyperactivity disorder: effects of treatment and non-treatment. BMC Med. 2012;10:99.

23. Meszaros A, Czobor P, Balint S, Komlosi S, Simon V, Bitter I. Pharmacotherapy of adult attention deficit hyperactivity disorder (ADHD): a metaanalysis. Int J Neuropsychopharmacol. 2009;12(8):1137-1147.

24. Wilens TE. Drug therapy for adults with attention-deficit hyperactivity disorder. Drugs. 2003;63(22):2395-2411.

25. Froehlich TE, Epstein JN, Nick TG, et al. Pharmacogenetic predictors of methylphenidate dose-response in attention-deficit/hyperactivity disorder. J Am Acad Child Adolesc Psychiatry. 2011;50(11):1129-1139. e1122.

26. Greenhill LL, Abikoff HB, Arnold LE, et al. Medication treatment strategies in the MTA Study: relevance to clinicians and researchers. J Am Acad Child Adolesc Psychiatry. 1996;35(10):1304-1313.

27. Vitiello B, Severe JB, Greenhill LL, et al. Methylphenidate dosage for children with ADHD over time under controlled conditions: lessons from the MTA. J Am Acad Child Adolesc Psychiatry. 2001;40(2): 188-196.

28. Coghill D, Banaschewski T, Zuddas A, Pelaz A, Gagliano A, Doepfner M. Long-acting methylphenidate formulations in the treatment of attention-deficit/hyperactivity disorder: a systematic review of head-to-head studies. BMC Psychiatry. 2013;13:237.

29. National Institute for Health and Care Excellence [NICE] guidelines for the treatment of adult ADHD; 2008. Available from: https://www. nice.org.uk/guidance/cg72. Accessed February, 2016.

30. Canadian Attention Deficit Hyperactivity Disorder Resource Alliance (CADDRA): Canadian ADHD Practice Guidelines; 2014. Available from: https://caddra.ca/pdfs/caddraGuidelines2011.pdf. Accessed February, 2016.

31. Wolraich M, Brown L, Brown RT, et al. ADHD: clinical practice guideline for the diagnosis, evaluation, and treatment of attention-deficit/ hyperactivity disorder in children and adolescents. Pediatrics. 2011; 128(5):1007-1022.

32. American Psychiatric Association. Practice Guideline for the Treatment of Patients with Major Depressive Disorder. 3rd edn. Washington, DC: American Psychiatric Publishing; 2010.

33. Asherson P, Manor I, Huss M. Attention-deficit/hyperactivity disorder in adults: update on clinical presentation and care. NeuropsychiatryLond. 2014;4:109-128.

34. Huss M, Ginsberg Y, Tvedten T, et al. Methylphenidate hydrochloride modified-release in adults with attention deficit hyperactivity disorder: a randomized double-blind placebo-controlled trial. Adv Ther. 2014; 31(1):44-65.

35. Medori R, Ramos-Quiroga JA, Casas M, et al. A randomized, placebocontrolled trial of three fixed dosages of prolonged-release OROS methylphenidate in adults with attention-deficit/hyperactivity disorder. Biol Psychiatry. 2008;63(10):981-989.

36. Spencer TJ, Adler LA, McGough JJ, et al. Efficacy and safety of dexmethylphenidate extended-release capsules in adults with attention-deficit/ hyperactivity disorder. Biol Psychiatry. 2007;61(12):1380-1387. 
37. Stein MA, Sarampote CS, Waldman ID, et al. A dose-response study of OROS methylphenidate in children with attention-deficit/hyperactivity disorder. Pediatrics. 2003;112(5):e404.

38. Wigal SB, Nordbrock E, Adjei AL, Childress A, Kupper RJ, Greenhill L. Efficacy of methylphenidate hydrochloride extended-release capsules (Aptensio $\mathrm{XR}^{\mathrm{TM}}$ ) in children and adolescents with attention-deficit/ hyperactivity disorder: a phase III, randomized, double-blind study. CNS Drugs. 2015;29(4):331-340.

39. Rapport MD, DuPaul GJ, Kelly KL. Attention deficit hyperactivity disorder and methylphenidate: the relationship between gross body weight and drug response in children. Psychopharmacol Bull. 1989; 25(2):285-290.

40. Cherma MD, Josefsson M, Rydberg I, et al. Methylphenidate for treating ADHD: a naturalistic clinical study of methylphenidate blood concentrations in children and adults with optimized dosage. Eur $J$ Drug Metab Pharmacokinet. 2017;42(2):295-307.

41. Douglas VI, Barr RG, Amin K, O’Neill ME, Britton BG. Dosage effects and individual responsivity to methylphenidate in attention deficit disorder. J Child Psychol Psychiatry. 1988;29(4):453-475.

42. Swedish Medical Products Agency. ADHD drugs - treatment guidelines. The Swedish Medical Products Agency. 2016;2:13-24.

43. Ritalin LA [package insert] Novartis Pharmaceuticals Corporation. East Hanover, NJ; June 2015. Available from: https://www.pharma.us.novartis. com/product/pi/pdf/ritalin_la.pdf. Accessed February, 2016.

44. Aptensio XR [package insert] Patheon Manufacturing Services LLC. Greenville, NC; April 2015. Available from: http://www.aptensioxr. com/resources/full-prescribing-information.pdf. Accessed February, 2016.

45. CONCERTA [package insert] ALZA Corporation. Mountain View, CA; March 2007. Available from: http://www.accessdata.fda.gov/ drugsatfda_docs/label/2007/021121s014lbl.pdf. Accessed February, 2016.

46. Daytrana [package insert] Shire Pharmaceuticals Ireland Limited; March 2007. Available from: http://www.accessdata.fda.gov/drugsatfda_docs/ label/2007/021514s005lbl.pdf. Accessed February, 2016.

47. Metadate ER [package insert] Mallinckrodt Inc. Hazelwood, MO; June 2015. Available from: www2.mallinckrodt.com/WorkArea/ DownloadAsset.aspx?id=2147483760. Accessed February, 2016.

48. Metadate CD [package insert] UCB, Inc., Smyrna, GA; August 2008. http://www.accessdata.fda.gov/drugsatfda_docs/label/2009/ 021259s021lbl.pdf. Accessed February, 2016.

49. Health NZMo. New Zealand Guidelines for the Assessment and Treatment of Attention-Deficit/Hyperactivity Disorder. Wellington: Ministry of Health; 2001.

50. Takahashi N, Koh T, Tominaga Y, Saito Y, Kashimoto Y, Matsumura T. A randomized, double-blind, placebo-controlled, parallel-group study to evaluate the efficacy and safety of osmotic-controlled release oral delivery system methylphenidate $\mathrm{HCl}$ in adults with attentiondeficit/hyperactivity disorder in Japan. World J Biol Psychiatry. 2014;15:488-498.

51. Goodman DW, Surman CB, Scherer PB, Salinas GD, Brown JJ. Assessment of physician practices in adult attention-deficit/hyperactivity disorder. Prim Care Companion CNS Disord. 2012;14(4).

52. Epstein JN, Kelleher KJ, Baum R, et al. Variability in ADHD care in community-based pediatrics. Pediatrics. 2014;134(6):1136-1143.

53. Huss M, Ginsberg Y, Arngrim T, et al. Open-label dose optimization of methylphenidate modified release long acting (MPH-LA): a post hoc analysis of real-life titration from a 40 -week randomized trial. Clin Drug Investig. 2014;34(9):639-649.

54. Buitelaar JK, Ramos-Quiroga JA, Casas M, et al. Safety and tolerability of flexible dosages of prolonged-release OROS methylphenidate in adults with attention-deficit/hyperactivity disorder. Neuropsychiatr Dis Treat. 2009;5:457-466.

55. Adler LA, Orman C, Starr HL, et al. Long-term safety of OROS methylphenidate in adults with attention-deficit/hyperactivity disorder: an open-label, dose-titration, 1-year study. J Clin Psychopharmacol. 2011;31(1):108-114.
56. Greenhill LL, Swanson JM, Vitiello B, et al. Impairment and deportment responses to different methylphenidate doses in children with ADHD: the MTA titration trial. J Am Acad Child Adolesc Psychiatry. 2001; 40(2):180-187.

57. Fredriksen M, Halmoy A, Faraone SV, Haavik J. Long-term efficacy and safety of treatment with stimulants and atomoxetine in adult ADHD: a review of controlled and naturalistic studies. Eur Neuropsychopharmacol. 2013;23(6):508-527.

58. Bonvicini C, Faraone SV, Scassellati C. Attention-deficit hyperactivity disorder in adults: a systematic review and meta-analysis of genetic, pharmacogenetic and biochemical studies. Mol Psychiatry. 2016; 21(7):872-884.

59. Fredriksen M, Dahl AA, Martinsen EW, Klungsoyr O, Haavik J, Peleikis DE. Effectiveness of one-year pharmacological treatment of adult attention-deficit/hyperactivity disorder (ADHD): an openlabel prospective study of time in treatment, dose, side-effects and comorbidity. Eur Neuropsychopharmacol. 2014;24(12): 1873-1884.

60. Gajria K, Lu M, Sikirica V, et al. Adherence, persistence, and medication discontinuation in patients with attention-deficit/hyperactivity disorder - a systematic literature review. Neuropsychiatr Dis Treat. 2014;10:1543-1569.

61. Cortese S, Panei P, Arcieri R, et al. Safety of methylphenidate and atomoxetine in children with attention-deficit/hyperactivity disorder (ADHD): data from the Italian National ADHD Registry. CNS Drugs. 2015; 29:865-877.

62. Murray ML, Insuk S, Banaschewski T, et al. An inventory of European data sources for the long-term safety evaluation of methylphenidate. Eur Child Adolesc Psychiatry. 2013;22(10):605-618.

63. Ginsberg Y, Arngrim T, Philipsen A, et al. Long-term (1 year) safety and efficacy of methylphenidate modified-release long-acting formulation (MPH-LA) in adults with attention-deficit hyperactivity disorder: a 26-week, flexible-dose, open-label extension to a 40-week, doubleblind, randomised, placebo-controlled core study. CNS Drugs. 2014; 28(10):951-962.

64. Buitelaar JK, Trott GE, Hofecker M, et al. Long-term efficacy and safety outcomes with OROS-MPH in adults with ADHD. Int $J$ Neuropsychopharmacol. 2012;15(1):1-13.

65. Findling RL, Wigal SB, Bukstein OG, et al. Long-term tolerability of the methylphenidate transdermal system in pediatric attention-deficit/ hyperactivity disorder: a multicenter, prospective, 12-month, openlabel, uncontrolled, phase III extension of four clinical trials. Clin Ther. 2009;31(8):1844-1855.

66. Zhang S, Faries DE, Vowles M, Michelson D. ADHD Rating Scale IV: psychometric properties from a multinational study as a clinician-administered instrument. Int J Methods Psychiatr Res. 2005; 14(4):186-201.

67. Leon AC, Olfson M, Portera L, Farber L, Sheehan DV. Assessing psychiatric impairment in primary care with the Sheehan Disability Scale. Int J Psychiatry Med. 1997;27(2):93-105.

68. Buitelaar JK, Casas M, Philipsen A, et al. Functional improvement and correlations with symptomatic improvement in adults with attention deficit hyperactivity disorder receiving long-acting methylphenidate. Psychol Med. 2012;42(1):195-204.

69. Storebo OJ, Krogh HB, Ramstad E, et al. Methylphenidate for attentiondeficit/hyperactivity disorder in children and adolescents: cochrane systematic review with meta-analyses and trial sequential analyses of randomised clinical trials. BMJ. 2015;351:h5203.

70. Ginsberg Y, Arngrim T, Philipsen A, et al. Safety profile of methylphenidate hydrochloride-modified release (MPH-LA) in adults and children with attention deficit hyperactivity disorder. Eur Psychiat. 2014;29(Suppl 1):1.

71. Nutt DJ, Fone K, Asherson P, et al. Evidence-based guidelines for management of attention-deficit/hyperactivity disorder in adolescents in transition to adult services and in adults: recommendations from the British Association for Psychopharmacology. J Psychopharmacol. 2007; 21(1):10-41. 
72. Bolea-Alamanac B, Nutt DJ, Adamou M, et al. Evidence-based guidelines for the pharmacological management of attention deficit hyperactivity disorder: update on recommendations from the British Association for Psychopharmacology. J Psychopharmacol. 2014;28(3):179-203.

73. Taylor E, Döpfner M, Sergeant J, et al. European clinical guidelines for hyperkinetic disorder-first upgrade. Eur Child Adolesc Psychiatry. 2004; 13(Suppl 1):17-30.

74. Lee TC, Hashim AH, Kuan CS, et al. Clinical practice guidelines. Management of attention deficit hyperactivity disorder in children and adolescents; 2008. Available from: http://www.acadmed.org.my/index. cfm?\&menuid=67\#Mental_Health.

75. National Health and Medical Research Council. Clinical Practice Points on the Diagnosis, Assessment and Management of Attention Deficit Hyperactivity Disorder in Children and Adolescents. Commonwealth of Australia. 2012
76. Scottish Intercollegiate Guidelines Network. Management of Attention Deficit and Hyperactivity Disorders in Children and Young People-A National Clinical Guideline. editors. Scottish Intercollegiate Guidelines Network (SIGN); 2009.

77. Development Group of the Clinical Practice Guideline on Attention Defi cit Hyperactivity Disorder (ADHD) in Children and Adolescents. Fundació Sant Joan de Déu, coordinator. Clinical Practice Guideline on Attention Deficit Hyperactivity Disorder (ADHD) in Children and Adolescents. Quality Plan for the National Health System of the Ministry of Health, Social Policies and Equality. Agència dinformació, Avaluació i Qualitat (AIAQS) of Catalonia. Clin Practice Guidelines Spanish NHS (SNS). 2010.
Neuropsychiatric Disease and Treatment

\section{Publish your work in this journal}

Neuropsychiatric Disease and Treatment is an international, peerreviewed journal of clinical therapeutics and pharmacology focusing on concise rapid reporting of clinical or pre-clinical studies on a range of neuropsychiatric and neurological disorders. This journa is indexed on PubMed Central, the 'PsycINFO' database and CAS,

\section{Dovepress}

and is the official journal of The International Neuropsychiatric Association (INA). The manuscript management system is completely online and includes a very quick and fair peer-review system, which is all easy to use. Visit http://www.dovepress.com/testimonials.php to read real quotes from published authors.

Submit your manuscript here: http://www.dovepress.com/neuropsychiatric-disease-and-treatment-journal 